\title{
Distância interincisiva máxima em crianças na dentadura mista
}

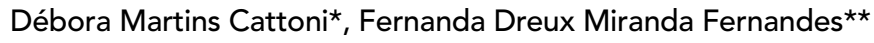

\section{Resumo}

A distância interincisiva máxima é muito importante na avaliação miofuncional orofacial, pois distúrbios miofuncionais orofaciais e cervicais podem limitar a abertura da boca. O objetivo deste estudo foi descrever a distância interincisiva máxima e verificar se há diferença estatisticamente significante entre as médias desta medida, segundo idade e gênero. Participaram 253 crianças, com idades entre 7,0 e 11,11 anos, leucodermas, na dentadura mista, sem queixas fonoaudiológicas. Os resultados mostram que a média da distância interincisiva máxima foi, no total das crianças, $44,75 \mathrm{~mm}$ e apresentou diferença estatisticamente significante entre as médias das idades, no gênero masculino. As meninas apresentaram médias inferiores às dos meninos. Como conclusão da pesquisa, aponta-se a importância de considerar a idade e o gênero durante a avaliação da distância interincisiva máxima em crianças

Palavras-chave: Face. Medidas. Boca. Criança.

\section{INTRODUÇÃO}

O interesse para a realização desta pesquisa cresceu à medida em que se observou a escassez de estudos nacionais sobre os referenciais da normalidade, em crianças da nossa população, para a distância interincisiva máxima, bem como de padronização dos critérios de avaliação empregados. Dado que os indivíduos com distúrbios miofuncionais orofaciais e cervicais podem apresentar limitações na abertura da boca, revela-se a importância de investigar a medida esperada para as estruturas faciais em crianças saudáveis, para melhor análise dos dados obtidos durante a avaliação fonoaudiológica.

Faz-se importante a investigação sobre a distância interincisiva máxima, pois verifica-se limitação da abertura da boca e da distância interincisiva máxima nos portadores de distúrbios que envolvem a articulação têmporo-mandibular ${ }^{3}$, bem como nas vítimas de queimaduras de face e pescoço, ocasionando seqüelas da motricidade oral e disfunções estomatognáticas, entre elas a abertura bucal reduzida ${ }^{16}$.

Durante a avaliação miofuncional oral, investigase os aspectos morfológicos e posturais, do tônus e da mobilidade dos órgãos fonoarticulatórios, bem como das funções de mastigação, respiração, deglutição e fala ${ }^{10}$, incluindo o exame da sensibilidade da região orofacial $^{7}$ e da postura corporal ${ }^{12}$.

A avaliação fonoaudiológica da motricidade oral envolve a constatação da existência de alterações funcionais e de relações desencadeantes do problema,

* Fonoaudióloga clínica. Especialização em Saúde Coletiva pela Faculdade de Medicina Medicina da Universidade de São Paulo (FMUSP). Especialista em Motricidade Oral pelo Conselho Federal de Fonoaudiologia (CFFa). Mestre em Ciências pela FMUSP.

* Fonoaudióloga. Professora Livre-Docente do Curso de Fonoaudiologia da Faculdade de Medicina da Universidade de São Paulo (FMUSP). 
como alterações dentoesqueléticas e/ou articulares ${ }^{3}$. Sendo assim, o principal objetivo da avaliação é verificar a presença de desequilibrios musculares e funcionais que prejudiquem o funcionamento do sistema estomatognático. Determinando-se o diagnóstico e as suas relações, pode-se obter maior clareza quanto ao prognóstico e melhores resultados terapêuticos ${ }^{1}$.

Marchesan ${ }^{12}$ e Ríspoli e Bacha ${ }^{14}$ propõem a utilização do paquímetro para mensurar os lábios superior e inferior, o filtro, os terços da face, as mordidas (aberta, sobressaliência) e a distância entre o canto externo do olho e a comissura dos lábios. De acordo com Marchesan ${ }^{11}$, o uso desse instrumento é fundamental para a avaliação do sistema estomatognático. Os dados obtidos a partir deste procedimento podem ser comparados antes e após o tratamento miofuncional oral e podem determinar as possibilidades para obtenção da funcionalidade do sistema estomatognático.

Bianchini $^{3}$ propõe a utilização do paquímetro para medir a distância interincisiva máxima, isto é, a distância entre os incisivos superiores e inferiores, na maior abertura possivel da boca. Tal instrumento também é utilizado para medir a abertura máxima da boca, considerada como a distância entre os incisivos superiores e inferiores, somando-se a marcação da sobremordida ou subtraindo-se a distância da mordida aberta anterior.

De acordo com Douglas ${ }^{6}$, a abertura da boca ocorre quando há simultaneamente o relaxamento dos músculos levantadores da mandíbula e contração dos músculos abaixadores da mandíbula. O músculo pterigóideo lateral é considerado o principal músculo abaixador da mandíbula e, também, realiza a protrusão da mandíbula, além dos movimentos de lateralidade, quando há contração unilateral do lado ativo e relaxamento contralateral do lado passivo. Bradley ${ }^{4}$ e Bianchini ${ }^{2}$ comentam que a musculatura infra-hióidea estabiliza a posição do osso hióide, fixando-o para a realização do movimento de abertura da boca. Carvalho ${ }^{5}$ descreve que a abertura da mandíbula é resultado da contração dos músculos abaixadores da mandibula, dos supra-hióideos e dos infra-hióideos.

Bianchini ${ }^{2}$ refere que os índices de normali- dade para abertura máxima de boca variam entre $45 \mathrm{~mm}$ e $60 \mathrm{~mm}$ para o adulto, sendo que a abertura inferior a $40 \mathrm{~mm}$ no adulto e inferior a $35 \mathrm{~mm}$ na criança, é um alerta de possíveis problemas musculares e/ou articulares. Hamazaki et al. ${ }^{9}$ encontraram, em seu estudo com crianças de 6 a 12 anos de idade, que a média para a abertura da boca foi $48,33 \mathrm{~mm}$, sendo que essa medida aumenta de acordo com a idade. Ríspoli e Bacha ${ }^{14}$ apontam que a abertura máxima de boca é de 40 a $45 \mathrm{~mm}$, não fazendo distinção entre os gêneros nem entre as idades. Rodrigues ${ }^{15}$ considera $40 \mathrm{~mm}$ como valor de referência da amplitude da boca em abertura máxima, em adultos.

Os objetivos da pesquisa foram descrever a distância interincisiva máxima e verificar se há diferença estatisticamente significante entre as médias da distância interincisiva máxima, segundo idade e gênero.

\section{MÉTODO}

Os responsáveis pelas crianças autorizaram a realização da pesquisa, assinando o Termo de Consentimento Livre e Esclarecido aprovado pela Comissão de Ética de Projetos de Pesquisa (CAPPesq) da Diretoria Clínica do Hospital das Clínicas e da Faculdade de Medicina da Universidade de São Paulo (nº 668/01).

Foram avaliadas 253 crianças, na faixa etária entre 7,0 e 11,11 anos, 136 do gênero masculino (54\%) e 117 do gênero feminino (46\%), freqüentadoras de escolas particulares da cidade de São Paulo. As crianças foram divididas de acordo com a idade, sendo que constituiram-se 5 grupos, a saber: 48 crianças de 7,0 a 7,11 anos; 51 crianças de 8,0 a 8,11 anos; 50 crianças de 9,0 a 9,11 anos; 54 crianças de 10,0 a 10,11 anos e 50 crianças de 11,0 a 11,11 anos.

Os critérios de seleção das crianças para inclusão neste estudo foram: a) histórico fonoaudiológico

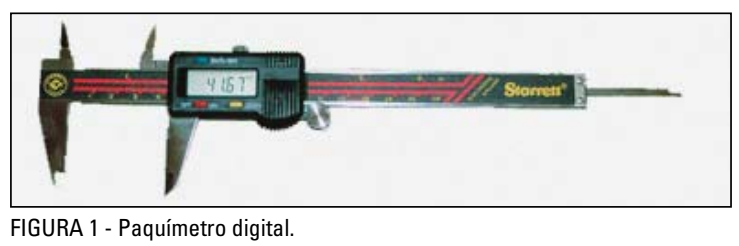


negativo-inexistênciadequeixa(s)fonoaudiológica(s), independentemente da área (voz, linguagem, motricidade oral e/ou audição), e/ou de histórico de tratamento fonoaudiológico prévio e/ou atual; b) leucoderma e c) dentadura mista com a erupção completa dos quatro primeiros molares permanentes.

O material utilizado foi luva cirúrgica, algodão, álcool etílico hidratado, detergente e o paquímetro digital Starrett Série 727 (Fig. 1).

Durante a coleta da distância interincisiva máxima, foi solicitado a cada criança que permanecesse sentada, com os pés apoiados no chão, com a cabeça em posição de repouso. Foi verificado se a criança era leucoderma e se estava em dentadura mista com os quatro primeiros molares permanentes completamente erupcionados. Nas crianças que apresentaram essas características, seguiu-se com a coleta da medida. A distância interincisiva máxima foi coletada na visão frontal e transcrita em milímetros para o protocolo de registro de dados.

A medida da distância interincisiva máxima (Fig. 2) correspondeu à distância entre a face incisal do dente incisivo central superior direito e a face incisal do dente incisivo central inferior direito, após a abertura possível da boca.

$\mathrm{Na}$ ausência dos dentes incisivos centrais superior e/ou inferior direitos, foi medida a distância

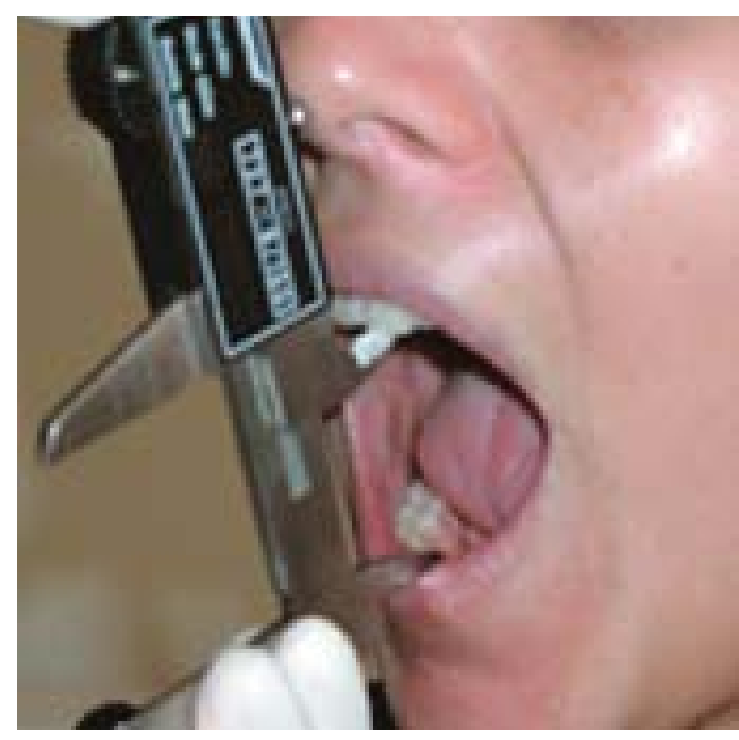

FIGURA 2 - Distância interincisiva máxima entre os dentes correspondentes do lado esquerdo. Na ausência dos incisivos centrais superiores e/ou inferiores, direitos e esquerdos, foi medida a distância entre a face incisal do dente incisivo lateral superior direito e a face incisal do dente incisivo lateral inferior direito. Na impossibilidade de se obter essa última medida em decorrência de falta dos dentes incisivos centrais e laterais do lado direito, foi medida a distância entre a face incisal do dente incisivo lateral superior esquerdo e a face incisal do dente incisivo lateral inferior esquerdo. $\mathrm{Na}$ ausência dos incisivos centrais e laterais inferiores e superiores, essa medida não foi obtida.

Ao final da avaliação de cada sujeito, as luvas cirúrgicas foram inutilizadas e as hastes do paquímetro foram lavadas com água e detergente e desinfetadas com álcool etílico hidratado, friccionado com algodão.

\section{ANÁLISE ESTATÍSTICA}

A população de estudo foi caracterizada por meio de estatística descritiva. Foi avaliada a aderência à curva Normal pelo uso do teste de Komolgorov-Smirnov. $\mathrm{Na}$ análise dos dados foi realizada a comparação das médias da distância interincisiva máxima, separadamente para meninos e meninas, segundo idade, por meio da análise de variância a 1 fator. Ao ser detectada diferença estatisticamente significante entre as médias, foram feitas as comparações múltiplas utilizando o teste de Tukey-HSD (honest significant differences) para estabelecer em qual idade havia diferença significante. Em todas as análises utilizou-se o nível de significância (p) de 5\%.

\section{RESULTADOS}

Considerando o número total de crianças, a média da distância interincisiva máxima foi $44,75 \mathrm{~mm}$, sendo que a mediana foi $44,65 \mathrm{~mm}$. O valor mínimo obtido foi $32,34 \mathrm{~mm}$, sendo que o valor máximo foi $58,01 \mathrm{~mm}$. Os dados descritos podem ser visualizados na figura 3 , onde observase que todas as medidas têm distribuição normal. $\mathrm{Na}$ tabela 1, pode-se observar que houve diferença estatisticamente significante entre as médias da 
distância interincisiva máxima, sendo que aos 7 anos de idade a média foi menor do que a encontrada aos 11 anos de idade $(\mathrm{p}=0,026)$. O mesmo ocorreu ao se comparar as médias aos 8 e aos 11 anos de idade $(\mathrm{p}=0,010)$. Para o gênero feminino, não houve diferença estatisticamente significante entre as médias $(\mathrm{p}=0,679)$. Vale salientar que as médias para o gênero masculino foram superiores às do feminino, exceto aos 8 anos de idade (Fig. 4)

\begin{tabular}{|c|c|c|c|c|}
\hline \multirow{5}{*}{ Tabela 1 - Estatística descritiva da distância interincisiva } \\
máxima segundo idade e gênero.
\end{tabular}

Legenda: $\mathrm{mm}=$ milímetros; $\mathrm{IC}=$ intervalo de confiança.

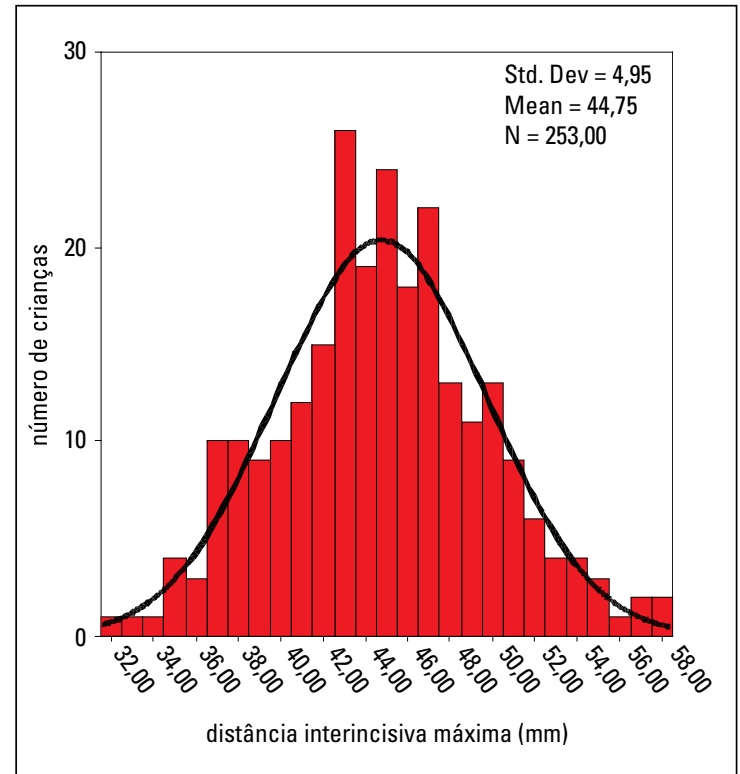

FIGURA 3 - Distribuição da distância interincisiva máxima.

\section{DISCUSSÃO}

Realizou-se a coleta de dados para ambos os gêneros, a fim de se detectar diferenças nas medidas de acordo com o gênero. A amostra deste estudo foi composta de $54 \%$ de crianças do gênero masculino e de $46 \%$ de crianças do gênero feminino, sendo que, em geral, as médias das medidas faciais obtidas para os meninos foram superiores daquelas obtidas para as meninas, conforme apontado na literatura. Ainda, uma vez constatada diferença estatística entre os dados somente no gênero masculino, entre 7 e 11 anos de idade e entre 8 anos e 11 anos de idade, sugere-se que mais estudos sejam realizados, com populações mais extensas, para melhor compreensão a respeito desta diferença.

Optou-se pela aplicação da metodologia indicada por Bianchini ${ }^{3}$ para obtenção da distância interincisiva máxima. Para aumentar a confiabilidade das medidas, os procedimentos foram realizados somente por um fonoaudiólogo, para não haver diferença entre observadores.

Quanto aos critérios empregados na seleção das crianças, participaram somente crianças sem queixa(s) fonoaudiológica(s) e sem tratamento fonoaudiológico atual e/ou prévio, uma vez que indivíduos portadores de distúrbios miofuncionais orofaciais e cervicais podem apresentar limitações de abertura da boca.

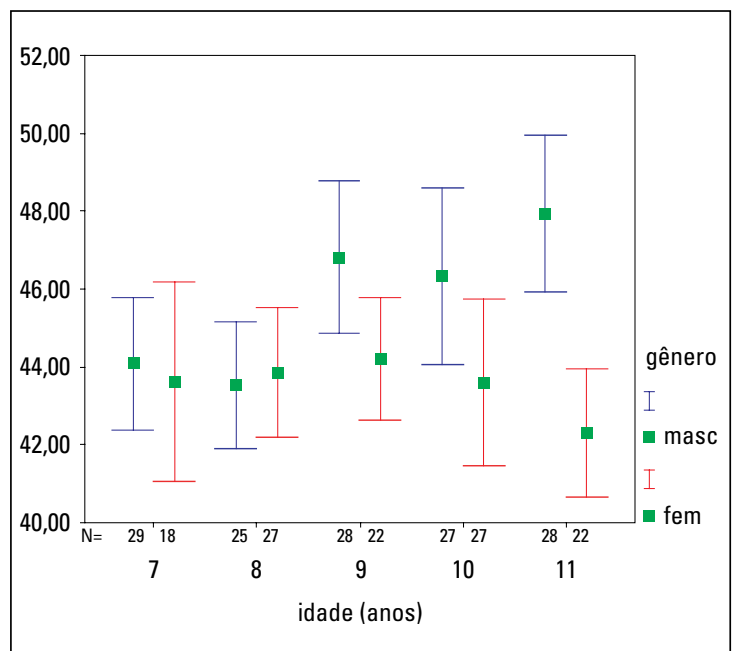

FIGURA 4 - Média da distância interincisiva máxima segundo idade e gênero. 
A dentadura mista foi o período de desenvolvimento da dentadura escolhido, sendo que a presença dos quatro primeiros molares permanentes erupcionados também foi critério para selecionar as crianças, uma vez que importantes transformações ocorrem na cavidade oral, entre os 5 e 6 anos de idade, em decorrência da erupção desses dentes ${ }^{8,13}$. Assim, foi possivel obter uma amostra mais homogênea quanto ao desenvolvimento da dentadura.

\section{CONCLUSÃO}

A média da distância interincisiva máxima foi, no total das crianças, $44,75 \mathrm{~mm}$ e apresentou diferença estatisticamente significante entre as médias das idades, no gênero masculino.

As meninas apresentaram médias inferiores às dos meninos, exceto aos 8 anos de idade.

\title{
Maximum interincisal distance in children in mixed dentition period
}

\begin{abstract}
The maximum interincisal distance is very important during the orofacial myofunctional evaluation, because orofacial myofunctional disorders can modify this measurement. The aim of this study was to describe the maximum interincisal distance and to verify if there is statistically significant difference among the averages of this measurement, according age and gender. 253 children participated, with ages ranging from 7,0 to 11,11 years, leukoderm, in mixed dentition period, with no history of speech and swallowing disorders. The results showed that the average of the maximum interincisal distance was $44,75 \mathrm{~mm}$ and showed statistically significant difference among averages according age, in male. Girls showed lower averages than boys. As conclusion of this reseach, it is observed the importance of considering the age and the gender during the evaluation of the maximum interincisal distance.
\end{abstract}

Key words: Face. Measurements. Mouth. Child.

\section{REFERÊNCIAS}

1. BIANCHINI, E. M. G. Avaliação fonoaudiológica da motricidade oral: distúrbios miofuncionais orofaciais ou situações adaptativas. R Dental Press Ortodon Ortop Facial, Maringá, v. 6, n. 3 p. 73-82, maio/jun. 2001.

2. BIANCHINI, E. M. G. Mastigação e ATM: avaliação e terapia. In: MARCHESAN, I. Q. Fundamentos em fonoaudiologia: aspectos clínicos da motricidade oral. Rio de Janeiro: Guanabara Koogan, 1998. p. 37-49.

3. BIANCHINI, E. M. G. Avaliação fonoaudiológica da motricidade oral: anamnese, exame clínico, o quê e por que avaliar. In: BIANCHINI, E. M. G. (Org.). Articulação temporomandibular: implicações, limitações e possibilidades fonoaudiológicas. Carapicuíba: Pró-fono, 2000. p.191-253.

4. BRADLEY, R. Fisiologia oral básica. São Paulo: Panamericana, 1981

5. CARVALHO, G. D. Amamentação e o sistema estomatognático. In: CARVALHO, M. R.; TAMEZ, R. N. Amamentação: bases científicas para a prática profissional. Rio de Janeiro: Guanabara Koogan, 2002. p. 37-59.

6. DOUGLAS, C. R. Tratado de fisiologia aplicada à fonoaudiologia. São Paulo: Robe, 2002.

7. GOMES, I. C. D. et al. Avaliação e terapia da motricidade oral. In: FERREIRA, L. P. et al. Temas de fonoaudiologia. 5. ed. São Paulo: Loyola, 1993. p. 61-119.

8. GUEDES-PINTO, A. C.; ISSÁO, M. Manual de odontopediatria. 10. ed. São Paulo: Pancast, 1999.

9. HAMAZAKI, C. M. et al. Verificação da amplitude dos movimentos mandibulares em crianças. Cefac, São Paulo, v. 4, n.1, p. 35-39, jan./abr. 2002.
10. JUNQUEIRA, P. S. Avaliação miofuncional. In: MARCHESAN, I. Q. Fundamentos em Fonoaudiologia: aspectos clínicos da motricidade oral. Rio de Janeiro: Guanabara Koogan, 1998. p. 13-21.

11. MARCHESAN, I. Q. Avaliando e tratando o sistema estomatognático. In: LOPES-FILHO, O. (Ed.). Tratado de Fonoaudiologia. São Paulo: Roca, 1997. p. 763-780.

12. MARCHESAN, I. Q. Avaliação e terapia dos problemas da respiração. In: MARCHESAN, I. Q. Fundamentos em Fonoaudiologia: aspectos clínicos da motricidade oral. Rio de Janeiro: Guanabara Koogan, 1998. p. 23-36.

13. NAKATA, M.; WEI, S. H. Y. Guia de oclusão em odontopediatria. 2. ed. São Paulo: Ed. Santos, 1995.

14. RÍSPOLI, C. M.; BACHA, S. M. C. Terapia miofuncional: intervenção fonoaudiológica breve. In: MARCHESAN, I. Q.; ZORZI, J. L.; GOMES, I. C.(Org.). Tópicos em Fonoaudiologia. São Paulo: Lovise, 1998. p. 545-585.

15. RODRIGUES, L. Avaliação odontológica. In: BIANCHINI, E. M. G. (Org.). Articulação temporomandibular: implicações, limitações e possibilidades fonoaudiológicas. Carapicuíba: Pró-fono, 2000. p.133-166.

16. TOLEDO, P. N. Atuação fonoaudiológica com pacientes queimados: uma proposta clínica. 2001. Dissertação (Mestrado) Pontifícia Universidade Católica, São Paulo, 2001.

\section{Endereço para correspondência}

Débora Martins Cattoni

Rua Paulo Franco, 142 - Apto. 111 - São Paulo/SP - CEP: 05305-030

E-mail: dmcattoni@uol.com.br 